\title{
Computer-based virtual reality colonoscopy simulation improves patient-based colonoscopy performance
}

\author{
Keith S Mclntosh MD FRCPC, James C Gregor MD FRCPC, Nitin V Khanna MD FRCPC
}

\begin{abstract}
KS McIntosh, JC Gregor, NV Khanna. Computer-based virtual reality colonoscopy simulation improves patient-based colonoscopy performance. Can J Gastroenterol Hepatol 2014;28(4):203-206.
\end{abstract}

BACKGROUND: Colonoscopy simulators that enable one to perform computer-based virtual colonoscopy now exist. However, data regarding the effectiveness of this virtual training are limited.

OBJECTIVE: To determine whether virtual reality simulator training translates into improved patient-based colonoscopy performance.

METHODS: The present study was a prospective controlled trial involving 18 residents between postgraduate years 2 and 4 with no previous colonoscopy experience. These residents were assigned to receive $16 \mathrm{~h}$ of virtual reality simulator training or no training. Both groups were evaluated on their first five patient-based colonoscopies. The primary outcome was the number of proctor 'assists' required per colonoscopy. Secondary outcomes included insertion time, depth of insertion, cecal intubation rate, proctor- and nurse-rated competence, and patient-rated pain.

RESULTS: The simulator group required significantly fewer proctor assists than the control group (1.94 versus 3.43 ; $\mathrm{P} \leq 0.001)$, inserted the colonoscope further unassisted $(43 \mathrm{~cm}$ versus $24 \mathrm{~cm} ; \mathrm{P}=0.003)$ and there was a trend to intubate the cecum more often $(26 \%$ versus $10 \%$; $\mathrm{P}=0.06)$. The simulator group received higher ratings of competence from both the proctors $(2.28$ versus 1.88 of $5 ; \mathrm{P}=0.02)$ and the endoscopy nurses ( 2.56 versus 2.05 of $5 ; \mathrm{P}=0.001)$. There were no significant differences in proctor-, nurse- or patient-rated pain, or attention to discomfort.

CONCLUSIONS: Computer-based colonoscopy simulation in the initial stages of training improved novice trainees' patient-based colonoscopy performance.

Key Words: Clinical competence; Colonoscopy; Computer simulation; Educational measurement

\section{La simulation virtuelle de la coloscopie améliore l'exécution de la coloscopie auprès des patients}

HISTORIQUE : Il existe désormais des simulateurs de coloscopie qui permettent d'effectuer une coloscopie virtuelle. Cependant, les données sur l'efficacité de cette formation virtuelle sont limitées.

OBJECTIF : Déterminer si la formation par simulateur virtuel se traduit par une meilleure exécution de la coloscopie auprès des patients.

MÉTHODOLOGIE : Les chercheurs ont mené la présente étude prospective contrôlée auprès de 18 résidents de la $2^{\mathrm{e}}$ à la $4^{\mathrm{e}}$ année d'études postdoctorales sans expérience antérieure de la coloscopie. Ces résidents ont reçu soit 16 heures de formation par simulateur virtuel, soit aucune formation. Les deux groupes ont été évalués lors de leurs cinq premières coloscopies auprès des patients. L'issue primaire était le nombre d'aides demandées au surveillant par coloscopie. Les issues secondaires incluaient le temps d'insertion, la profondeur de l'insertion, le taux d'intubation cæcale, la compétence évaluée par un surveillant et par l'infirmière, ainsi que la douleur évaluée par le patient.

RÉSULTATS : Le groupe qui avait utilisé la simulation avait besoin de beaucoup moins d'aide que le groupe témoin (1,94 par rapport à 3,43; $\mathrm{P} \leq 0,001$ ), insérait le coloscope plus loin sans aide (43 $\mathrm{cm}$ par rapport à $24 \mathrm{~cm} ; \mathrm{P}=0,003$ ) et avait tendance à intuber le cæcum plus souvent ( $26 \%$ par rapport à $10 \% ; \mathrm{P}=0,06)$. Il a reçu de meilleures évaluations de compétence tant de la part des surveillants (2,28 par rapport à 1,88 sur $5 ; \mathrm{P}=0,02)$ que des infirmières en endoscopie (2,56 par rapport à 2,05 sur $5 ; \mathrm{P}=0,001)$. Il n'y avait pas de différence significative sur le plan de la douleur évaluée par le surveillant, l'infirmière ou le patient, ou de l'attention portée aux malaises.

CONCLUSIONS : La simulation virtuelle de la coloscopie aux premières phases de la formation améliore le rendement de stagiaires novices lors de coloscopies auprès des patients.
Derforming colonoscopy requires advanced technical skill that 1 demands significant time to learn and master. Traditional methods of learning this procedure involve trainees performing patient-based colonoscopy from the outset of training under the close supervision of a fully qualified endoscopist. This approach is laden with potential issues. Patients have reported increased dissatisfaction with procedures performed by trainees, particularly in the early stages of training. An increased frequency of minor adverse events associated with colonoscopy in this setting has also been described (1). Finally, teaching endoscopy has an impact on endoscopy unit efficiency. One study estimated that trainee involvement in endoscopy increases procedure time by $37 \%$ (2). The financial impact this may have on both the institution and clinician could be significant.

With the advancement of computer technology, there are now several virtual reality endoscopy simulators that hold promise in overcoming some of these challenges. One such simulator, the Simbionix
GI Mentor II (Simbionix Corporation, USA) enables the user to practice both upper and lower gastrointestinal endoscopy through several different simulated cases. Potential advantages in the training of endoscopy include a lack of actual patient involvement in the development of basic endoscopic techniques, precluding the possibility of patient dissatisfaction or adverse events. Time constraints in the endoscopy unit are not an issue because the trainee can devote as much time as needed to work through the modules. The major limitation in implementing widespread use of the simulators is cost. Currently, available systems range in price from $\operatorname{USD} \$ 50,000$ to $>\$ 100,000$ (3).

Several simulator validation studies have been performed showing that the simulators have excellent face and construct validity. These studies have shown that experts perform significantly better on the simulator than novices, as one would expect if the simulators provide a realistic representation of colonoscopy (4-8). To date, however, there

Division of Gastroenterology, Department of Medicine, Western University, London, Ontario

Correspondence and reprints: Dr Keith S McIntosh, St Joseph's Health Centre, 268 Grosvenor Street, London, Ontario N6A 4V2.

Telephone 519-646-6000 ext 64698, fax 519-646-6130, e-mail ksmcintosh@gmail.com

Received for publication November 15, 2013. Accepted February 7, 2014 
have only been a limited number of studies that have evaluated whether simulator training improves performance on real-life, patientbased procedures $(9,10)$. Our aim in the present study was to determine whether computer-based virtual reality simulator training improved patient-based colonoscopy performance in novice trainees.

\section{METHODS}

\section{Study design}

The present study was a prospective trial comparing simulator-trained residents with a control group of non-simulator-trained residents, all of whom were novice endoscopists. The residents were assigned to a simulator-training group or to a control group. Residents in the gastroenterology program at the start of their fellowship or residents selected to be in the gastroenterology program were assigned to the simulatortraining group. Similarly matched controls were selected from internal medicine residents interested in gastroenterology, general surgery residents with interest in endoscopy and gastroenterology residents who could not complete the simulator training before starting their fellowship. Preceptors were blinded as to who had received simulator training. The study received approval from the Western University Health Sciences Research Ethics Board (London, Ontario) (approval \#15688E, March 27, 2009).

\section{Study population}

Residents enrolled in internal medicine, gastroenterology or general surgery subspecialties between postgraduate years 2 and 4 were eligible to participate. The gastroenterology fellows were only eligible to participate before the start of their fellowship. Exclusion criteria included previous endoscopic experience, which was defined as having performed $>10$ previous upper endoscopies, sigmoidoscopies or colonoscopies.

For the patient-based colonoscopies, patients were included if they gave informed consent, were undergoing a screening or surveillance colonoscopy, were between 18 and 75 years of age and had previously undergone colonoscopy without reported difficulty. Patients were excluded if they failed to give consent or were not willing to complete the postendoscopy questionnaire.

\section{Intervention}

Residents assigned to the simulator-trained group were given an orientation and instruction session on the Simbionix GI Mentor II simulator. Orientation consisted of showing the participant how to operate the simulator and basic instruction on the controls of the colonoscope. The residents were then asked to complete between $10 \mathrm{~h}$ and $20 \mathrm{~h}$ of training on the simulator, which occurred over a period of approximately four weeks before performing patient-based colonoscopies. They were free to perform cases at their discretion, which included modules 1 to 10 of upper endoscopy and modules 1 to 10 of colonoscopy. They were not given any other specific teaching, but were free to ask questions or receive feedback on request. Training was considered to be complete once trainees could intubate the cecum on all 10 of the colonoscopy modules. On completion of simulator training, trainees were asked to complete a questionnaire regarding their impression of the usefulness of the simulator training sessions.

Before performing patient-based colonoscopy, both groups received a standardized $30 \mathrm{~min}$ tutorial on the basics of how to perform colonoscopy. This included familiarizing residents with the colonoscope and its controls, how to safely advance the colonoscope, and insufflate and reduce loops. This was the only teaching the control group received regarding colonoscopy, which was comparable with the degree of training a typical gastroenterology fellow would receive on the first day of their fellowship.

Both groups were evaluated on their first five consecutive patientbased colonoscopies. For each colonoscopy that the residents performed, they were given a $15 \mathrm{~min}$ time limit to intubate the cecum. As long as the resident was steadily progressing and advancing the colonoscope in a safe manner, they were allowed to continue the procedure. However, if no forward progress was made for a period of $2 \mathrm{~min}$ or the trainee was deemed to be performing an unsafe manoeuvre as judged by an observer, then the proctor provided 'an assist'. This entailed the proctor assuming control of the colonoscope and guiding it past the immediately encountered obstacle and then relinquishing control of the colonoscope back to the trainee. This routine was continued as necessary until the trainee reached the cecum or $15 \mathrm{~min}$ in total had passed. The residents were not evaluated on the withdrawal of the colonoscope.

To attempt to standardize the results, all cases were supervised by one of two blinded proctors. There was also a single individual who acted as an observer on all the cases. The observer timed the cases and recorded the data.

\section{Outcomes}

The primary outcome of the present study was the mean number of proctor assists required per colonoscopy. Other objective outcome measures included procedure time, 'median depth reached' $(1=$ rectum, 2 = sigmoid, 3 = descending colon, $4=$ splenic flexure, $5=$ trans verse colon, $6=$ hepatic flexure, $7=$ ascending colon, $8=$ cecum), 'mean depth of unassisted insertion' $(\mathrm{cm})$ and proportion of cases in which the cecum was successfully intubated.

Each patient-based procedure was evaluated by the supervising proctor and the endoscopy nurse assisting the case. The proctors and nurses rated the trainees on their technique on a five-point Likert scale. Patients were also asked to complete questionnaires after the procedure. This was performed in the recovery room once they met criteria for discharge. The patients were asked to rate their perceived level of discomfort and their overall satisfaction with the procedure on a five-point Likert scale.

\section{Statistical analysis}

Continuous data were analyzed using an unpaired $t$ test with two-tailed $\mathrm{P}$ values reported. Categorical data were analyzed using the Fisher's exact test with two-tailed $\mathrm{P}$ values; $\mathrm{P} \leq 0.05$ was considered to be statistically significant.

The sample size was determined based on the primary outcome, number of assists. In initial testing of the 'assists' methodology, it was estimated that the mean difference in number of assists between the groups would be at least 1 with an SD of 0.7. Based on this assumption, to show that simulator-trained residents required fewer assists than conventional trained residents with a power of $80 \%$ and $\alpha$ of 0.05 , eight subjects per group were required. Sample size calculations and statistical analysis was performed using Stata version 12 (StataCorp, USA).

\section{RESULTS}

In total, 18 residents were recruited to the present study, with 10 being assigned to the simulator-trained group and eight to the control group. The residents were from a mixed group of specialties including gastroenterology, general surgery and internal medicine. The simulatortrained and control groups were similarly matched for age, sex, level of training, interest in video games, hours playing video games per week and interest in endoscopic procedures. Both groups had little, if any, previous endoscopic experience. The intervention group consisted of more current gastroenterology fellows, although the eventual career path of the trainees resulted in 10 of 10 simulator-trained residents and six of eight control group residents going into gastroenterology or general surgery (Table 1 ).

The residents assigned to the simulator-trained group completed a mean $( \pm$ SD) $15.8 \pm 3.6 \mathrm{~h}$ of training on the simulator to demonstrate competence on all 10 modules. The mean number of simulated cases completed was $49 \pm 14$. Residents in the simulator-trained group completed a postsimulator training questionnaire. In evaluating the amount of time on the simulator, the mean score was $3.1 \pm 0.6(1=$ too little, $3=$ just right, $5=$ too much). Resident feedback on the simulator training was very positive. On a five-point Likert scale, they rated the usefulness of simulator training as 4.1 and their overall satisfaction as $4.2(1=$ low, 5 = high $)$. 
TABLE 1

Trainee baseline characteristics

\begin{tabular}{lcc}
\hline Characteristic & $\begin{array}{c}\text { Simulator group } \\
(\mathbf{n}=10)\end{array}$ & $\begin{array}{c}\text { Control } \\
\text { group }(\mathbf{n}=\mathbf{8})\end{array}$ \\
\hline Male sex & 90 & 100 \\
Age, years, mean & 29 & 29 \\
Level of training, $\mathrm{n}$ & & \\
$\quad$ 2nd-year resident & 0 & 2 \\
3rd-year resident & 2 & 4 \\
$\quad$ 4th-year resident & 8 & 2 \\
Current specialty, $\mathrm{n}$ & & \\
$\quad$ Internal medicine & 2 & 5 \\
$\quad$ Gastroenterology & 8 & 2 \\
$\quad$ General surgery & 0 & 1 \\
Gastroenterology or general surgery as & 100 & 75 \\
$\quad$ eventual specialty & & \\
Time devoted to playing video & 2.3 & 1.9 \\
$\quad$ games, h/week & & \\
Interest in playing video games (1 to 10) & 5.0 & 4.7 \\
Self-rated skill at playing video games & 5.5 & 5.8 \\
$\quad$ (1 to 10) & & \\
Self-rated interest in endoscopy (1 to 10) & 8.7 & 9.0 \\
Trainees with previous endoscopic & 60 & 50 \\
$\quad$ experience & & \\
Endoscopic cases, mean \pm SD & & \\
$\quad$ Upper endoscopies & $1.9 \pm 2.3$ & $0.9 \pm 2.1$ \\
$\quad$ Flexible sigmoidoscopies & $0.4 \pm 0.7$ & \\
Colonoscopies & 0 & \\
\hline
\end{tabular}

Data presented as \% unless otherwise indicated

Because each trainee performed five colonoscopies, 90 patients were recruited. The average age of the patients was 59 years, and patient sex was evenly split between male and female. There were no significant differences between the groups in endoscopic findings or sedation received. Approximately two-thirds of the colonoscopies had normal findings (Table 2).

The predefined primary outcome was the number of proctor assists required per colonoscopy. There was a statistically significant difference between the groups, with the simulator-trained group requiring $1.94 \pm 0.81$ assists per colonoscopy compared with $3.43 \pm 0.39$ assists per colonoscopy for the control group $(\mathrm{P}=0.004)$.

Also recorded were several prespecified secondary outcome measures. Mean depth of unassisted insertion was significantly greater in the simulator-trained group $(44 \pm 14 \mathrm{~cm}$ versus $24 \pm 7 \mathrm{~cm} ; \mathrm{P}=0.003)$. There was a trend toward inserting the colonoscope further in the simulator-trained group who, on average, reached the hepatic flexure, whereas the control group reached only the transverse colon $(\mathrm{P}=0.09)$. There was also a strong trend toward intubating the cecum more often in the simulator-trained group ( $26 \%$ versus $10 \% ; \mathrm{P}=0.06)$. The total insertion time did not differ significantly between the groups because both groups approached the $15 \mathrm{~min}$ time limit $(14.4 \pm 0.6 \mathrm{~min}$ for simulator group versus $14.6 \pm 0.5 \mathrm{~min}$ for control group; $\mathrm{P}=0.37)$. Results are shown in Table 3.

The endoscopy nurses and the proctors evaluated the residents' overall technique and skill with respect to performing colonoscopy. The nurses and proctors were blinded to who had received simulator training. Both groups ranked the simulator-trained residents as having better technique than the nonsimulator-trained residents. The proctors rated the simulator trained group $2.28 \pm 0.21$ compared with $1.88 \pm 0.45$ for the control group on a five-point Likert scale $(\mathrm{P}=0.02)$. Ratings were as follows: 1 for poor technique, 3 for competent and 5 for expert. The nurses had similar evaluations, rating the simulator group $2.56 \pm 0.26$ versus $2.05 \pm 0.28$ for the control group $(P=0.001)$.

The patients completed questionnaires about their perceived colonoscopy experience. With regard to pain, patients reported
TABLE 2

Patient baseline characteristics

\begin{tabular}{lcc}
\hline Characteristic & $\begin{array}{c}\text { Simulator group } \\
(\mathbf{n}=\mathbf{5 0})\end{array}$ & $\begin{array}{c}\text { Control group } \\
(\mathbf{n}=\mathbf{4 0})\end{array}$ \\
\hline Age, years, mean & 59 & 60 \\
Male sex & 50 & 51 \\
Colonoscopy findings & & \\
$\quad$ Normal & 66 & 69 \\
Polyp & 28 & 25 \\
$\quad$ Diverticulosis & 14 & 18 \\
$\quad$ Other & 4 & 5 \\
Sedation & & \\
Fentanyl, $\mu \mathrm{g}$, mean $\pm \mathrm{SD}$ & $91 \pm 21$ & $95 \pm 13$ \\
Midazolam, mg, mean \pm SD & $4.72 \pm 1.57$ & $4.75 \pm 1.74$ \\
\hline
\end{tabular}

Data presented as \% unless otherwise indicated.

minimal levels of discomfort, with no significant differences between the groups $(1.98 \pm 0.48$ for simulator group versus $1.95 \pm 0.33$ for control group; $\mathrm{P}=0.9)(0=$ no pain, $5=$ extreme pain $)$. With respect to level of satisfaction with the procedure, both simulator-trained and control groups received high scores in this category $(4.36 \pm 0.32$ for simulator group versus $4.58 \pm 0.31$ for control group; $\mathrm{P}=0.17)(0=$ totally unsatisfied, 5 = extremely satisfied).

\section{DISCUSSION}

There is obvious appeal to the use of simulators to assist in training. Before implementing the widespread use of simulators in training, however, we must ensure its validity. To date, most of the validation studies have investigated the face and construct validity of simulators, which, although important, does not demonstrate the transferability of skills to patient-based procedures. In the present study, we demonstrated that simulator training does lead to improved patient-based colonoscopy performance in the early stages of training.

The simulator-trained residents outperformed non-simulatortrained residents in a variety of metrics in the present study. For our primary outcome measure, the simulator-trained group needed almost 1.5 fewer proctor assists per colonoscopy than the control group, which was both statistically and clinically significant. 'Assists' was chosen as our primary outcome measure because this was believed to be the best way to mimic real-life colonoscopy training early on. Typical methods of measuring colonoscopy competence, such as cecal intubation rate, polyp detection rate and perforation rate, are not appropriate for the assessment of a novice trainee. Even measuring time to reach the cecum does not apply to the first five to 10 procedures. We acknowledge that this measure has not been previously validated; however, it has excellent face validity and similar methods of measuring the amount of proctor assistance have been used to assess competence at performing endoscopic ultrasound (11).

Other areas in which the simulator-trained residents outperformed the non-simulator-trained residents included the mean depth of unassisted insertion and proportion of cases in which the cecum was successfully intubated. The simulator-trained residents also received higher ratings on their assessed technical skill by proctors and nurses who were observing for proper lumen visualization, safe advancement and appropriate use of the colonoscope. At present, a validated tool for this type of assessment is lacking.

Interestingly, patient feedback was not significantly different between the two groups. Patients reported minimal levels of pain and high levels of satisfaction regardless of whether their colonoscopy was performed by the simulator- or non-simulator-trained residents. We postulate several explanations for this finding. The first is that the discomfort experienced by the two groups was masked by adequate levels of sedation provided by the proctor. Second, we believe our method of providing assists may have improved patient comfort. There are points in the procedure in which a resident encounters difficulty, such as with loop formation, resulting in the potential for the patient 
TABLE 3

\section{Performance characteristics}

\begin{tabular}{lccc}
\hline Outcome & Simulator group & Control group & $\mathbf{P}$ \\
\hline Assists, n, mean & 1.94 & 3.43 & 0.004 \\
Insertion time, min, mean & 14.4 & 14.6 & 0.37 \\
Landmark reached & Hepatic flexure & $\begin{array}{c}\text { Transverse } \\
\text { colon }\end{array}$ & 0.09 \\
Cecal intubation rate, \% & 26 & 10 & 0.06 \\
$\begin{array}{l}\text { Depth of unassisted } \\
\text { insertion, cm, mean }\end{array}$ & 44 & 24 & 0.003 \\
\hline
\end{tabular}

to experience pain. In our protocol, the proctor would intervene to provide assistance, such as loop reduction, thereby minimizing discomfort. These good patient satisfaction scores support the use of our preferred method of providing 'assists' when teaching colonoscopy to a novice on a real patient.

With regard to the simulator training itself, residents reported being highly satisfied with the experience. The residents indicated that the training was useful and most believed the length of time on the simulator was appropriate. The mean length of training time was almost $16 \mathrm{~h}$, which is significantly more than previous studies evaluating the simulator. Only one recent study using the Olympus colonoscopy simulator (Olympus, Japan) had a similar amount of training (12). The longer duration of simulator training may have helped to maximize the performance benefit apparent in the simulator-trained group. Two aspects of the simulator that were not believed to provide an accurate representation of patient-based colonoscopy based on expert and resident evaluation were air insufflation and tactile feedback.

Previous studies have shown benefit of simulators in the early stages of training but that advantage is lost once significant endoscopic experience is acquired $(9,10)$. Therefore, we specifically focused on the initial stages of training in the present study. We did not follow the residents' progress as they acquired more endoscopic experience to determine whether the performance advantage is maintained. Nevertheless, we believe the initial performance advantage shown by the simulator-trained residents justifies the utility of the simulator by enabling the resident to begin their training at a higher level of competency and confidence.

There were several limitations to our study. The present study was not randomized, resulting in a slight predominance of fourth-year

\section{REFERENCES}

1. Bini EJ, Firoozi B, Choung RJ, et al. Systematic evaluation of complications related to endoscopy in a training setting: A prospective 30-day outcomes study. Gastrointest Endosc 2003;57:8-16

2. McCashland T, Brand R, Lyden E, et al. The time and financial impact of training fellows in endoscopy. CORI Research Project. Clinical Outcomes Research Initiative. Am J Gastroenterol 2000;95:3129-32

3. Bittner JG, Marks JM, Dunkin BJ, et al. Resident training in flexible gastrointestinal endoscopy: A review of current issues and options. J Surg Educ 2007;64:399-409.

4. Sedlack RE, Kolars JC. Validation of a computer-based colonoscopy simulator. Gastrointest Endosc 2003;57:214-8.

5. Eversbusch A, Grantcharov TP. Learning curves and impact of psychomotor training on performance in simulated colonoscopy: A randomized trial using a virtual reality endoscopy trainer. Surg Endosc 2004;18:1514-8.

6. Felsher JJ, Olesevich M, Farres H, et al. Validation of a flexible endoscopy simulator. Am J Surg 2005;189:497-500. residents who were gastroenterology fellows in the simulator-trained group. This was largely a result of the requirement that locally trained gastroenterology fellows complete simulator training before starting their fellowship. However, because the present study was completed before the residents started their gastroenterology fellowship, they had essentially no previous endoscopic experience and, thus, we believe the difference between a beginning fourth-year gastroenterology fellow and a second- or third-year resident is likely to be of little consequence. This was reinforced by the fact that a significant majority of both groups eventually went into gastroenterology or general surgery and were well matched for video game experience and interest in endoscopy; therefore, we believe there is unlikely to be significant bias in the composition of the groups. Second, patient recall questionnaires were likely influenced by the sedation received. This would affect both groups equally, however, because there were no significant differences in the level of sedation. Finally, our primary end point of assists had not been previously validated, although as previously mentioned, has excellent face validity.

There are several future areas of study that will serve to enhance the use of simulators in residency training. It warrants further study whether the addition of feedback during simulator training may serve to enhance patient-based colonoscopy performance even further Additionally, the utility of simulators for early training in therapeutic manoeuvres, such as polypectomy, should be a basis for future studies.

\section{CONCLUSION}

We have shown that simulator-trained residents performed better than nonsimulator-trained residents at patient-based colonoscopy in the early stages of training. Based on the findings of the present study and other recent publications, there is strong evidence to support the use of endoscopy simulators as a training tool for novice endoscopists. The implementation of simulators as part of routine training is likely to shorten the learning curve for patient-based procedures and enables the novice endoscopist to learn in a lowpressure environment free from time constraints. With the increasing amount of literature validating simulators, it is likely that their use in training will continue to expand.

DISCLOSURES: The authors have no financial disclosures or conflicts of interest to declare.

7. Grantcharov TP, Carstensen L, Schulze S. Objective assessment of gastrointestinal endoscopy skills using a virtual reality simulator. JSLS 2005;9:130-3.

8. Koch AD, Buzink SN, Heemskerk J, et al. Expert and construct validity of the Simbionix GI Mentor II endoscopy simulator for colonoscopy. Surg Endosc 2008;22:158-62.

9. Sedlack RE, Kolars JC, Alexander JA. Computer simulation training enhances patient comfort during endoscopy. Clin Gastroenterol Hepatol 2004;2:348-52.

10. Cohen J, Cohen SA, Vora KC, et al. Multicenter, randomized, controlled trial of virtual-reality simulator training in acquisition of competency in colonoscopy. Gastrointest Endosc 2006;64:361-8.

11. Wani S, Cote GA, Keswani K, et al. Learning curves for EUS by using cumulative sum analysis: Implications for ASGE recommendations for training. Gastrointest Endosc 2013;77:558-65.

12. Haycock A, Koch AD, Familiari P, et al. Training and transfer of colonoscopy skills: A multinational, randomized, blinded, controlled trial of simulator versus bedside training. Gastrointest Endosc 2010;71:298-307. 


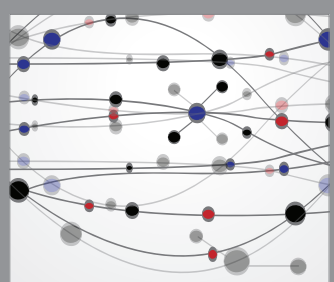

The Scientific World Journal
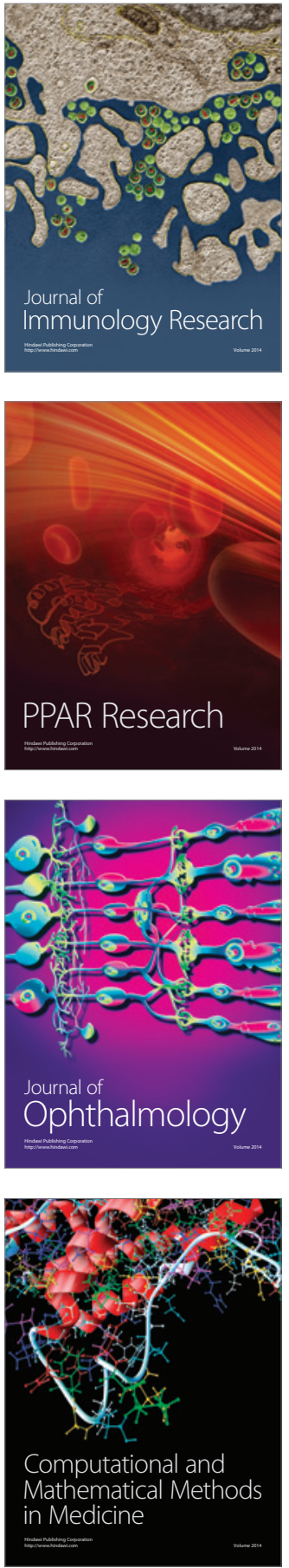

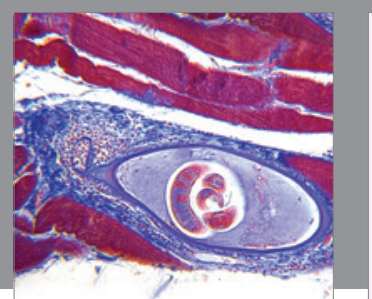

Gastroenterology Research and Practice

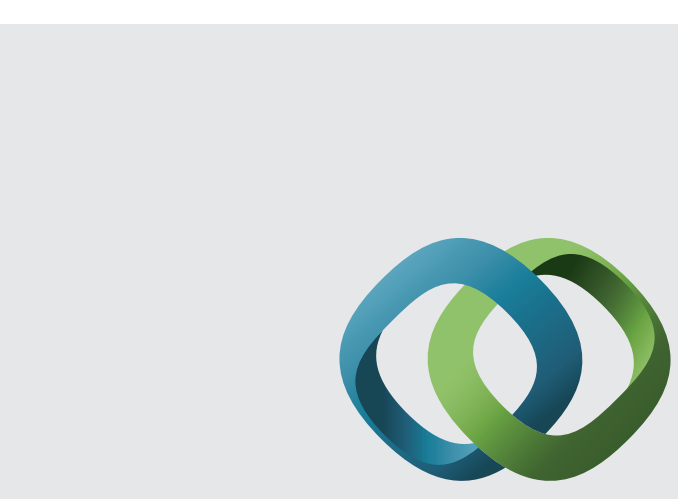

\section{Hindawi}

Submit your manuscripts at

http://www.hindawi.com
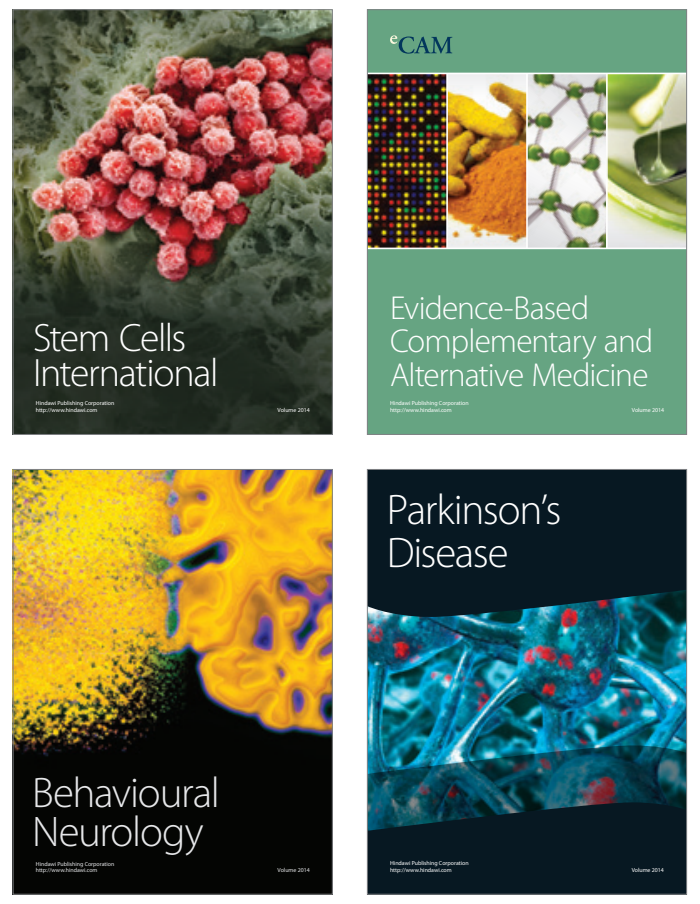
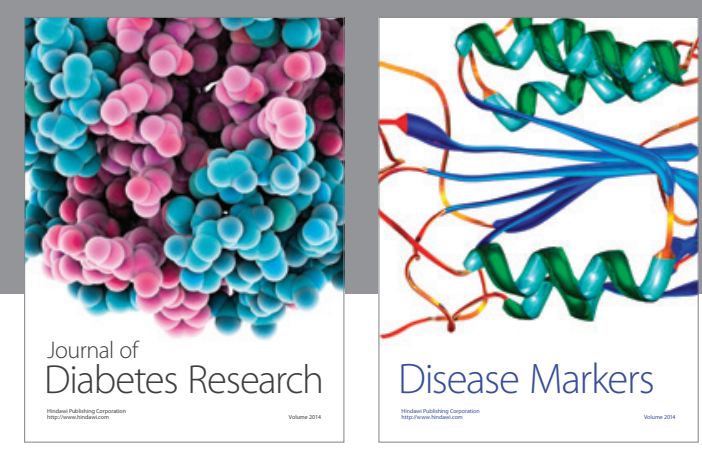

Disease Markers
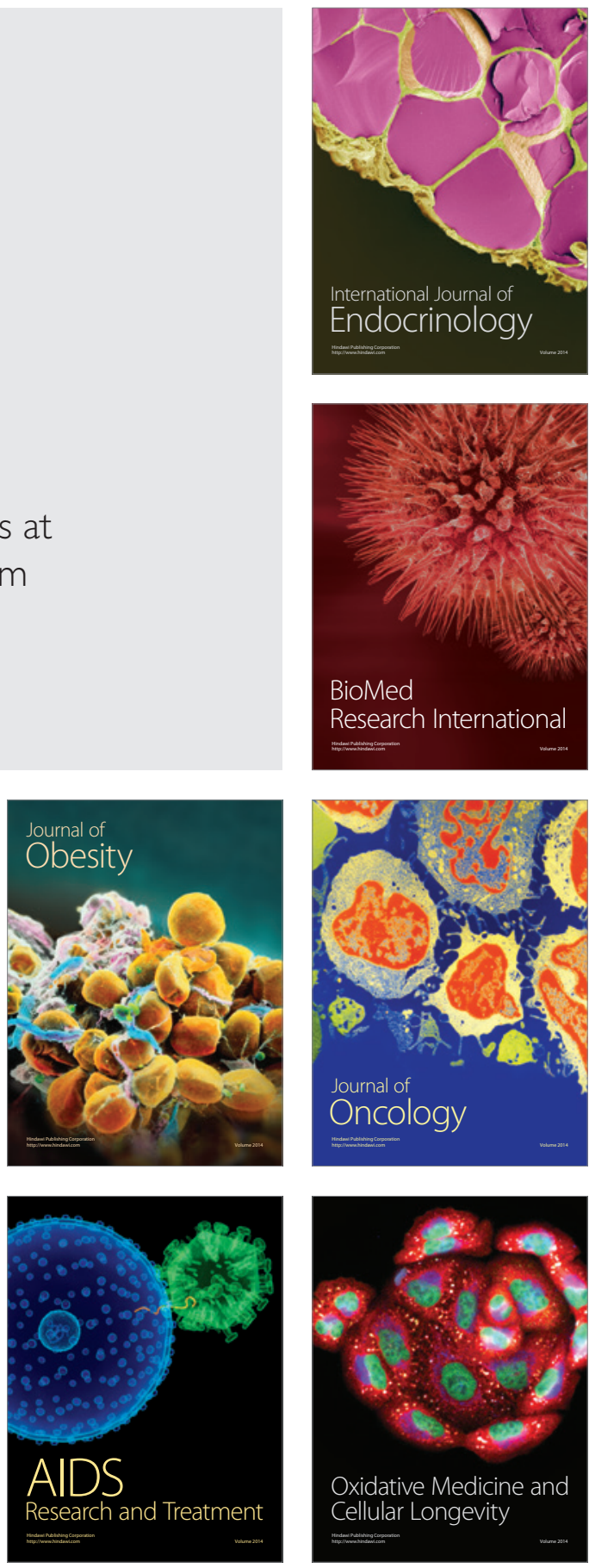